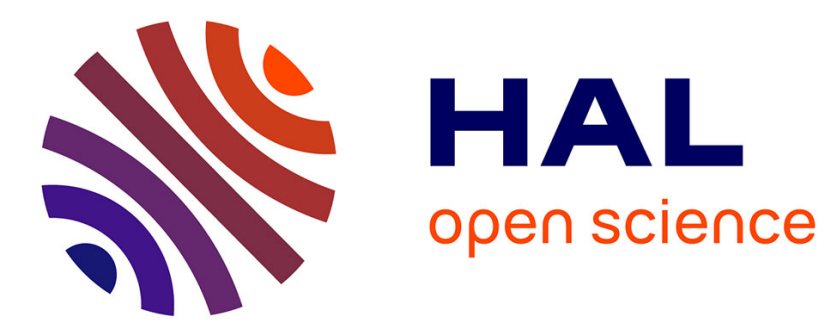

\title{
Re-alignment of the eyes, with prisms and with eye surgery, affects postural stability differently in children with strabismus
}

Agathe Legrand, Emmanuel Bui-Quoc, Maria Pia Bucci

\section{To cite this version:}

Agathe Legrand, Emmanuel Bui-Quoc, Maria Pia Bucci. Re-alignment of the eyes, with prisms and with eye surgery, affects postural stability differently in children with strabismus. Graefe's Archive for Clinical and Experimental Ophthalmology, 2012, 250 (6), pp.849-855. 10.1007/s00417-011-1845-z . hal-03137449

\author{
HAL Id: hal-03137449 \\ https://hal.science/hal-03137449
}

Submitted on 25 Feb 2021

HAL is a multi-disciplinary open access archive for the deposit and dissemination of scientific research documents, whether they are published or not. The documents may come from teaching and research institutions in France or abroad, or from public or private research centers.
L'archive ouverte pluridisciplinaire HAL, est destinée au dépôt et à la diffusion de documents scientifiques de niveau recherche, publiés ou non, émanant des établissements d'enseignement et de recherche français ou étrangers, des laboratoires publics ou privés. 


\title{
Re-alignment of the eyes, with prisms and with eye surgery, affects postural stability differently in children with strabismus
}

\author{
Agathe Legrand • Emmanuel Bui-Quoc • \\ Maria Pia Bucci
}

\begin{abstract}
Aim The purpose of the study was to examine the effect of eye re-alignment (after wearing prisms and after eye surgery) on postural stability in children with strabismus. Methods Nine children with strabismus (6-13 years old) participated in the study. A posturography platform (TechnoConcept) was used to examine posture in quiet stance at two distances: steady fixation of a target at near distance $(40 \mathrm{~cm})$ and at far distance $(200 \mathrm{~cm})$. Four different conditions were tested: with and without prisms before eye surgery, and twice after eye surgery.

Results The surface of the CoP increased after wearing prisms (540 $\mathrm{mm}^{2}$ compared to the condition without prisms $\left(462 \mathrm{~mm}^{2}\right)$; in contrast, eye surgery reduced the surface of the $\mathrm{CoP}$, leading to improved postural control $\left(454 \mathrm{~mm}^{2}\right.$ and $401 \mathrm{~mm}^{2}$, respectively, in the post 1 and post 2 surgery condition). Unlike normal children, strabismic children showed no improvement in postural control at near distance. Conclusions Binocular visual and motor changes affect body sway; adaptive mechanisms induced by eye realignment after surgery allow improved postural control. The absence of dependency on distance in postural stability in strabismic children could be due to their impaired depth perception and to the poor integrity of the visual signal required to control posture.
\end{abstract}

\footnotetext{
A. Legrand $\cdot$ M. P. Bucci $(\triangle)$

Laboratoire de Psychologie et Neuropsychologie Cognitives, FRE 3292 CNRS IUPDP Université Paris Descartes,

71 Avenue Edouard Vaillant,

92774 Boulogne Billancourt Cedex, France

e-mail: maria-pia.bucci@parisdescartes.fr

E. Bui-Quoc

Service d'Ophtalmologie, Hôpital Robert Debré,

48 Boulevard Sérurier,

75019 Paris, France
}

Keywords Strabismus · Children · Postural control - Eye surgery Prism adaptation

\section{Introduction}

The visual system is responsible for about $80 \%$ of our sensory perception. This system is important not only for cognition of objects but also because it gives the brain information about the body; the majority of our movements are controlled by our eyes. Vision is one of the most important inputs controlling posture and balance regulation, together with the somatosensory, proprioceptive and vestibular subsystems [1]. A recent study by Bucci et al. [2] showed that children suffering from vertigo due to abnormal vergence fusional capabilities had poor postural control compared to healthy children of similar age. This study suggests that binocular visual information, such as vergence disparity, is important for stabilizing posture.

Recently, Friedrich's research group [3] examined postural control in normal adults and adults with visual disabilities. They showed that, when visual inputs are deficient, compensation mechanisms such as vestibular and somatosensory inputs and cerebellar processes can be activated to ensure good postural control. Furthermore, Peterka [4] showed that adult subjects with bilateral vestibular loss were able to weight visual and proprioceptive information better than adult subjects with normal vestibular function. Peterka hypothesized that, when one sensory input (e.g., the vestibular system) is not working well, the other subsystems (e.g., visual and/or proprioceptive) compensate for the impairment by playing a greater role (see also Ravaioli et al. [5]).

About $4 \%$ of children develop strabismus during the first 6 years of life. The etiology of strabismus is still unknown 
and eye surgery is the most frequent treatment method [6]. To our knowledge, few studies have examined postural stability in children with strabismus. A report by Odenrick et al. [7] found that body sway was larger in children with esotropia. Note, however, that this study did not provide a detailed analysis of postural control. Matsuo et al. [8] reported large body sway in children with exotropia, particularly for children without stereoacuity; 3 days after surgery, the sway was found to be greater than before surgery. The authors concluded that this effect could be due to the changes in the proprioceptive information associated with the extra-ocular muscles after eye surgery. Note, however, that the effect of general anesthesia could be still present after 3 days. Recently, we reported that, about 8 weeks after strabismus surgery, children's postural stability had significantly improved, suggesting that the somatosensory properties of the extra-ocular muscles together with visual perception influenced body stability [9]. Such improvement was not due to restoration of binocular visual capabilities, because in children with early onset strabismus any binocular disparity capability was absent and eye surgery cannot restore binocular functions. Rather, eye surgery most likely leads to harmonization of ocular motility, improving visual inputs, and allowing good postural control. Indeed, in previous studies based on eye movement recordings $[2,10,11]$, we suggested that the re-alignment of the eyes via surgery allowed adaptive mechanisms take hold, promoting better saccade and vergence performance.

A recent study by Matsuo et al. [12] examined the effect of prismatic adaptation on postural control in strabismic adults. Seventeen subjects with constant or intermittent exotropia participated in the study. Postural control was measured four times: before prismatic adaptation, immediately after, $15 \mathrm{~min}$ after, and $60 \mathrm{~min}$ after wearing the prisms. The authors reported a significant increase in postural instability while the subjects were wearing prisms but $60 \mathrm{~min}$ after prismatic adaptation, postural stability reached the values measured before the adaptation. They did not report any difference between subjects with and without binocular capabilities.

In the present study, we wished to explore further how eye re-alignment (by wearing prisms and after eye surgery) could affect visual information, leading to a change in the quality of postural control in children with strabismus.

Furthermore, given that for these types of children, perception of distance and depth is lacking because of their vergence abnormalities [13] we also wanted to examine also whether distance from the object being focused on would affect these children's postural control. According to previous studies by another group [1] and our own, [2] it is well known that postural stability is better when focusing at a near distance than a far distance because of the easy detection of visual motion and oculomotor convergence signals. Our hypothesis was that, in children with strabismus, postural stability could be less distance-dependent than in normal children and adults.

\section{Materials and methods}

\section{Subjects}

\section{Clinical characteristics before surgery}

Nine children (6-13 years old) with strabismus participated in the study. Before surgery, all children underwent a complete ophthalmologic and orthoptic examination. The clinical characteristics of each child are shown in Table 1. Refraction was measured under cyclopentolate chlorhydrate $0.5 \%$, a drug allowing a temporary paresis of accommodation. Visual acuity was measured for each eye separately at far $(5 \mathrm{~m})$ and near $(30 \mathrm{~cm})$ distances with the Monoyer chart [14] and the Parinaud scale, respectively. Orthoptic tests showed the presence of strabismus, which was measured by the cover-uncover test and the bar of prisms. Seven children $(\mathrm{C} 1, \mathrm{C} 2, \mathrm{C} 3, \mathrm{C} 4, \mathrm{C} 5, \mathrm{C} 8$, and C9) had esotropia, which depended on viewing distance for five of them $(\mathrm{C} 1, \mathrm{C} 3, \mathrm{C} 4, \mathrm{C} 8$, and $\mathrm{C} 9)$; for all of them, the deviation was equal or larger than 30 prism diopters. One child (C6) had distance-dependent exotropia. One child (C7) had exophoria with vertical strabismus (upward deviation of the left eye). Children C6 and C7 presented stereopsis before surgery, as measured by the TNO test. All children had good visual acuity (superior or equal to 8/10). Four children had significant hypermetropia $(>$ to 3 diopters), three had relative hypermetropia ( $<3$ diopters), and one child did not wear glasses. Strabismus appeared early (before 2 years) in six children $(\mathrm{C} 2, \mathrm{C} 3, \mathrm{C} 4, \mathrm{C} 5, \mathrm{C} 8$ and $\mathrm{C} 9)$, while in three children ( $\mathrm{C} 1, \mathrm{C} 6$ and $\mathrm{C} 7)$ it appeared later on.

In order to eliminate the deviation and mimic eye surgery, the squint angle of each child was corrected by wearing Berens single square prism of different amount in front of each eye mounted on their glasses (see Table 1, prism correction column). More specifically, the amount of the deviation at a far distance (in prism diopters) was split over both sides by placing prisms of equal or nearly equal amounts in front of both eyes. All the children wore prisms for $1 \mathrm{~h}$; all of them were comfortable (no one complained of double vision) with the prisms after a few minutes of testing. During the adaptation period, the children were in the ophthalmologic department; they could play, read books or paint. They could also walk around inside the hospital. After $1 \mathrm{~h}$ of prism adaptation, an ophthalmologic and orthoptic examination was done of all children. Visual 
Table 1 Clinical characteristics of children examined. LE, RE: left eye, right eye; all subjects had good visual acuity for both eyes. The dominant eye was determined by using the 4-prism $\mathrm{D}$ base-out prism test: the prism was alternated over the left and the right eye; the eye for which the prism more frequently caused a re-fixation movement was considered dominant. The deviation of the eyes was assessed with several tests (e.g., cover-uncover test, prism, and synoptophore); binocular vision was evaluated with the TNO random dot test for stereoscopic depth discrimination. XT-XXT: exophoria-exotropia measured at far distance. X'T-X'X'T: exophoria-exotropia measured at near distance. ET-EET: esophoria-esotropia measured at far distance. E'T-E'E'T: esophoria-esotropia measured at near distance.
O and O': orthophoria at far and near distance, respectively. HLT and H'LT: hypertropia of the left eye measured at far and at near distance. HL and H'L: hyperphoria of the left eye measured at far and at near distance. Direction of the prisms on glasses: temporal based, (-) nasal based and based down. Type of surgical treatment: (a) recession medial rectus RE, LE, RE and LE; (b) recession medial rectus RE, LE, $\mathrm{RE}$ and $\mathrm{LE}$, and resection lateral rectus RE, LE, RE and LE; (c) resection lateral rectus $\mathrm{RE}, \mathrm{LE}, \mathrm{RE}$ and $\mathrm{LE}$; (d) recession lateral rectus RE, LE, RE and LE; (e) recession lateral rectus RE, LE, RE and LE, and resection medial rectus RE, LE, RE and LE; (f) recession superior rectus $R E, L E, R E$ and $L E$

\begin{tabular}{|c|c|c|c|c|c|c|c|c|c|c|c|c|}
\hline \multicolumn{9}{|l|}{ Pre-surgery } & \multicolumn{2}{|c|}{$\begin{array}{l}\text { Post } 1 \\
\text { (1 month after) }\end{array}$} & \multicolumn{2}{|c|}{$\begin{array}{l}\text { Post } 2 \\
\text { ( } 3 \text { month after) }\end{array}$} \\
\hline $\begin{array}{l}\text { Child (age } \\
\text { in years) }\end{array}$ & $\begin{array}{l}\text { Glasses } \\
\text { correction }\end{array}$ & $\begin{array}{l}\text { Corrected } \\
\text { visual } \\
\text { acuity }\end{array}$ & $\begin{array}{l}\text { Dominant } \\
\text { eye }\end{array}$ & $\begin{array}{l}\text { Squint } \\
\text { (prism D) }\end{array}$ & $\begin{array}{l}\text { TNO } \\
\text { test }\end{array}$ & $\begin{array}{l}\text { Prisms on } \\
\text { glasses, } \\
\text { prism D }\end{array}$ & $\begin{array}{l}\text { Squint after } \\
45 \mathrm{~min} \\
\text { prisms }\end{array}$ & $\begin{array}{l}\text { Eye } \\
\text { surgery }\end{array}$ & $\begin{array}{l}\text { Squint } \\
\text { (prism D) }\end{array}$ & $\begin{array}{l}\text { TNO } \\
\text { test }\end{array}$ & $\begin{array}{l}\text { Squint } \\
\text { (prism D) }\end{array}$ & $\begin{array}{l}\text { TNO } \\
\text { test }\end{array}$ \\
\hline \multirow[t]{2}{*}{ C1 (6) } & $\begin{array}{l}\text { RE: }+5.75 \\
\left(-1.75,5^{\circ}\right)\end{array}$ & RE: $10 / 10$ & \multirow[t]{2}{*}{$\mathrm{LE}$} & ET: 45 & - & LE: 25 & ET: 6 & \multirow[t]{2}{*}{$\begin{array}{l}\mathrm{b} \text { RE } \\
\quad(7 \mathrm{~mm})\end{array}$} & ET: 4 & \multirow[t]{2}{*}{ - } & ET: 4 & \multirow[t]{2}{*}{$400 "$} \\
\hline & $\begin{array}{l}\text { LE: }+5.75 \\
\quad\left(-1.5,20^{\circ}\right)\end{array}$ & LE: $10 / 10$ & & E’T: 50 & & RE: 20 & E’T: 12 & & EE'T: 10 & & EE'T: 10 & \\
\hline \multirow[t]{2}{*}{ C2 (6) } & $\begin{array}{l}\text { RE: }+2 \\
\quad\left(-0.75,170^{\circ}\right)\end{array}$ & RE: $10 / 10$ & \multirow[t]{2}{*}{$\mathrm{RE}$} & ET: 45 & - & LE: 16 & ET: 4 & \multirow[t]{2}{*}{$\begin{array}{r}\text { a RE, LE } \\
(4 \mathrm{~mm})\end{array}$} & ET: 4 & - & ET: 6 & \multirow[t]{2}{*}{-} \\
\hline & $\begin{array}{l}\text { LE: }+3.5 \\
\quad\left(-1.25,180^{\circ}\right)\end{array}$ & LE: $10 / 10$ & & E'T: 45 & & RE: 18 & E’T: 10 & & EE'T: 8 & & EE'T: 10 & \\
\hline \multirow[t]{2}{*}{ C3 (6) } & $\begin{array}{l}\text { RE: } 4 \\
\quad\left(-0.75,100^{\circ}\right)\end{array}$ & RE: $9 / 10$ & $\mathrm{RE}$ & ET: 35 & - & LE: 16 & Ortho & \multirow[t]{2}{*}{$\begin{array}{r}\text { a RE, LE } \\
(6 \mathrm{~mm})\end{array}$} & ET: 10 & - & ET: 6 & \multirow[t]{2}{*}{-} \\
\hline & $\begin{array}{l}\text { LE: } 4.5 \\
\quad\left(-1,90^{\circ}\right)\end{array}$ & LE: $10 / 10$ & & E'T: 45 & & RE: 14 & Ortho' & & E’T: 14 & & E’T: 6 & \\
\hline \multirow[t]{2}{*}{ C4 (8) } & $\begin{array}{l}\text { RE: }+2 \\
\quad\left(-0.50,20^{\circ}\right)\end{array}$ & RE: $10 / 10$ & $\mathrm{LE}$ & ET: 30 & - & LE: 14 & ET: 12 & \multirow[t]{2}{*}{$\begin{array}{l}\text { a RE, LE } \\
(4 \mathrm{~mm})\end{array}$} & ET: 18 & - & ET: 12 & \multirow[t]{2}{*}{-} \\
\hline & $\mathrm{LE}:+1.25$ & LE: $8 / 10$ & & E’T: 35 & & RE: 12 & E'T: 14 & & E’T: 25 & & E'T: 14 & \\
\hline \multirow[t]{2}{*}{ C5 (8) } & $\begin{array}{l}\text { RE: } 5.55 \\
\left(-3,20^{\circ}\right)\end{array}$ & RE: $10 / 10$ & $\mathrm{LE}$ & ET: 30 & - & LE: 10 & Ortho & \multirow[t]{2}{*}{$\begin{array}{l}\text { c RE, LE } \\
(5.5 \mathrm{~mm})\end{array}$} & ET: 8 & - & ET: 10 & \multirow[t]{2}{*}{ - } \\
\hline & $\begin{array}{l}\text { LE: }+6.75 \\
\left(-3,155^{\circ}\right)\end{array}$ & LE: $10 / 10$ & & E'T: 30 & & RE: 15 & Ortho' & & E’T: 20 & & E’T: 15 & \\
\hline \multirow[t]{2}{*}{ C6 (11) } & $\begin{array}{l}\text { RE: } 0 \\
\quad\left(-0.75,65^{\circ}\right)\end{array}$ & RE: $8 / 10$ & LE & XT: 35 & $200 "$ & LE:-16 & XT: 6 & \multirow[t]{2}{*}{$\begin{array}{l}\text { e RE } \\
\text { (4 mm) }\end{array}$} & $X: 4$ & $200 "$ & ET: 4 & \multirow[t]{2}{*}{$200 "$} \\
\hline & LE: -0.50 & LE: $10 / 10$ & & X’T: 20 & & RE:-18 & $\mathrm{X}^{\prime} \mathrm{T}: 2$ & & $X^{\prime}: 8$ & & E’T: 8 & \\
\hline \multirow[t]{3}{*}{ C7 (12) } & 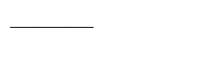 & RE: $10 / 10$ & \multirow[t]{3}{*}{$\mathrm{RE}$} & $\begin{array}{l}\text { XXT: } 2 \\
\text { HLT: } 10\end{array}$ & $60 "$ & $\begin{array}{l}\text { LE: } 10 \\
\text { based- }\end{array}$ & Ortho & \multirow[t]{3}{*}{ f LE (3 mm) } & X: 4 HL 3 & $60 "$ & $\begin{array}{l}\text { X: } 2 \\
\text { HL: } 2\end{array}$ & \multirow[t]{3}{*}{$60^{\prime}$} \\
\hline & & LE: $10 / 10$ & & XX'T: 4 & & down & Ortho' & & $X^{\prime}: 4 H^{\prime} L 3$ & & $X^{\prime}: 2$ & \\
\hline & & & & H'LT: 14 & & & & & & & H'L: 3 & \\
\hline \multirow[t]{2}{*}{ C8 (13) } & $\begin{array}{l}\text { RE: }-0.25 \\
\quad\left(-1.25,160^{\circ}\right)\end{array}$ & RE: $10 / 10$ & $\mathrm{RE}$ & ET: 30 & - & LE: 15 & ET: 0 & \multirow[t]{2}{*}{$\begin{array}{l}\text { a RE, LE } \\
(4 \mathrm{~mm})\end{array}$} & XT: 6 & - & XT: 6 & \multirow[t]{2}{*}{ - } \\
\hline & $\begin{array}{l}\text { LE: }+0.25 \\
\quad\left(-1.75,17^{\circ}\right)\end{array}$ & LE: $8 / 10$ & & E'T: 40 & & RE: 15 & E'T: 4 & & $\mathrm{X}^{\prime} \mathrm{T}: 4$ & & X'T: 10 & \\
\hline \multirow[t]{2}{*}{ C9 (13) } & $\mathrm{RE}:+0.25$ & RE: 9/10 & $\mathrm{RE}$ & ET: 30 & - & LE: 16 & ET: 10 & c RE, LE & ET: 14 & - & ET: 14 & - \\
\hline & $\begin{array}{l}\text { LE: }+0.50 \\
\quad\left(-.50,40^{\circ}\right)\end{array}$ & LE: $10 / 10$ & & E’T: 40 & & RE: 14 & E'T: 14 & $(5.5 \mathrm{~mm})$ & E’T: 20 & & E’T: 18 & \\
\hline
\end{tabular}

acuity was assessed and their deviation measured. It was reduced in all cases and near and far distance; orthophoria was assessed in two children (C5 and $\mathrm{C} 7$ ).

\section{Clinical characteristics after surgery (post 1 and post 2)}

All children underwent strabismus surgery: recession or tightening of the extra-ocular muscles. Four of them $(\mathrm{C} 2$, $\mathrm{C} 3, \mathrm{C} 4$, and $\mathrm{C} 8$ ) underwent bilateral medial rectus recession; one child $(\mathrm{C} 1)$ underwent medial rectus recession and lateral rectus resection; child $\mathrm{C} 6$ underwent lateral rectus recession and medial rectus resection; two children (C5 and C9) underwent bilateral medial lateral resection; and $\mathrm{C} 7$ underwent medial superior recession (see Table 1 for details).

One month after eye surgery, another ophthalmologic and orthoptic examination was done of all children. At this time, the squint angle was found to be reduced for all of them. Four children $(\mathrm{C} 1, \mathrm{C} 2, \mathrm{C} 3$ and $\mathrm{C} 5)$ showed slight esotropia $(<12 \mathrm{Dp})$, two children (C4 and C9) had esotropia greater than $12 \mathrm{Dp}$, and three children (C6, C7 and C8) had small exotropia $(<12 \mathrm{Dp})$. The stereopsis 
measured before surgery for two children (C6 and C7) remained at the same level afterward.

All children were examined a second time 3 months after the eye surgery, and the deviation was found to be stable or slightly improved with respect to the previous examination (see Table 1, Post 2). Importantly, one child (C1) with lateonset strabismus gained 400 " of stereopsis. Given the late onset of strabismus, this child had some potential for binocular vision.

The investigation adhered to the principles of the Declaration of Helsinki and was approved by our Institutional Human Experimentation Committee. Informed consent was obtained from the children's parents after the experimental procedure was explained to them.

\section{Platform}

A platform (strain gauge principle) consisting of two dynamometric clogs (standards by Association Française de Posturologie, produced by TechnoConcept, Céreste, France) was used to measure postural stability. The position of the feet was as follows: heels $4 \mathrm{~cm}$ apart and feet positioned symmetrically with respect to the child's sagittal axis at a $30^{\circ}$ angle. The arms hung vertically along the body. The excursions of the centre of pressure $(\mathrm{CoP})$ were measured for $51.2 \mathrm{~s}$ and the surface of the $\mathrm{CoP}$ was calculated following Gagey's standards (http://pierremarie. gagey.perso.sfr.fr/EllipseConfiance.htm); the equipment in- cluded a 16-bit analogue-digital converter. The sampling frequency of the CoP was $40 \mathrm{~Hz}$.

\section{Procedure}

The child was asked to fixate a target along the vertical midline at his/her eye level. The target was a human face that was either happy or sad (depending on the position of the mouth) displayed on a vertical screen. The angular size of the face was adjusted to subtend $1^{\circ}$ for both viewing distances tested $(40 \mathrm{~cm}$ and $200 \mathrm{~cm}$ ). Posturography was done in a normally furnished experimental room. The child was placed on the platform and asked to fixate the target face and to decide whether the face was happy or sad. Postural stability was recorded before surgery during steady fixation at a near distance $(40 \mathrm{~cm})$ and a far distance $(200 \mathrm{~cm})$ in two different conditions: binocular viewing without wearing prisms and $1 \mathrm{~h}$ after wearing prisms while the child still had the prisms on. After the strabismus surgery, the children were tested again twice: 1 month (post 1) and 3 months after surgery (post 2). In the post 1 and post 2 recordings, postural stability was recorded only under the binocular viewing condition without prisms for the two different distances $(40 \mathrm{~cm}$ and $200 \mathrm{~cm}$ ). Figure 1 shows the sway path of the center of pressure for each foot and in the middle the mean of the feet during postural recording for the different conditions tested at near distance from child C5. The order of the two
Fig. 1 The sway path of the center of pressure for each foot and in the middle the mean of the feet during postural recording from child $\mathrm{C} 5$ before surgery without (A) and with prisms (B), and in the post 1 (C) and post 2 (D) surgery condition recorded at near distance
A) Before surgery without prisms

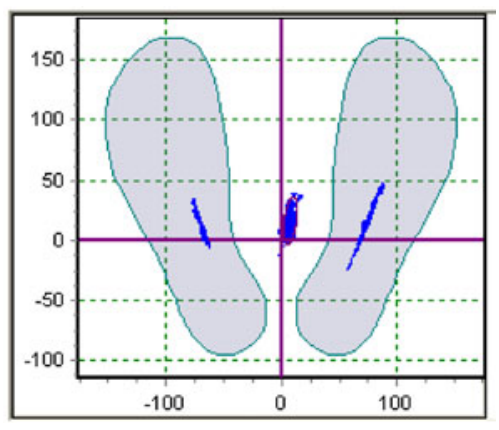

C) Post1 surgery

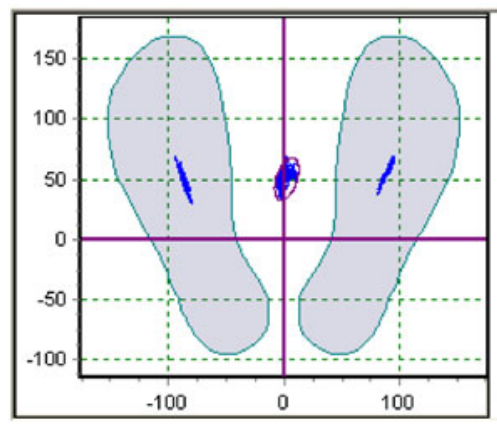

B) Before surgery with prisms

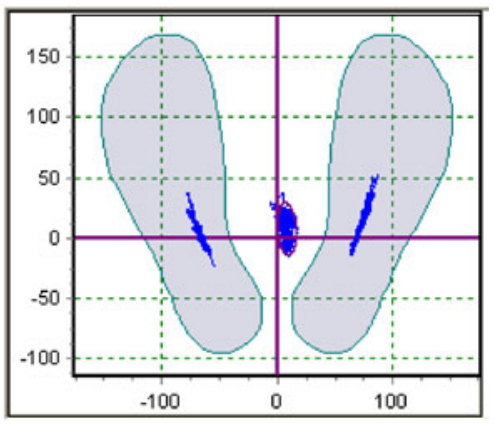

D) Post 2 surgery

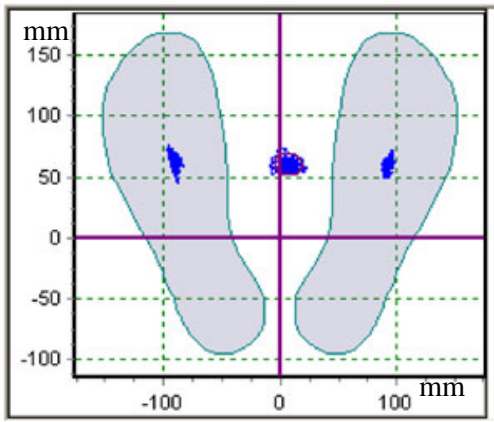


distances and of the conditions was assigned randomly between the children. Each test was followed by a rest of a few minutes.

\section{Data analysis}

The method of posture measurement is similar to that used previously [9]. We analyzed the surface and the variance of speed of the CoP excursion. Surface area is a good measure of CoP spatial variability [15] and the variance of speed represents a good index of the amount of neuromuscular activity required to regulate postural control [16].

Statistical analysis was performed using analyses of variance (ANOVAs); the within-subject factor was the deviation and the postural data from the different distances (near and far) for the different conditions (pre without prisms, pre with prisms, post 1 and post 2). The effect of a factor is significant when the $p$ value is below 0.05 .

\section{Results}

Deviation changes in the different conditions tested

We run the ANOVA on the values of the deviation before and after prism wearing and in the post 1 and post 2 surgery condition. The ANOVA showed a significant effect of condition $\left(F_{(3,24)}=17.99, p<0.0001\right.$ and $F_{(3,24)}=23.51, p<$ 0.0001 , respectively, for the deviation measured at far and at near distance), but the least significant difference post hoc test showed only a significant difference between the pre and the other conditions. Note that the deviation measured after prism wearing was not significant different with respect to the two post surgery conditions. In a similar way, the deviation measured in the two post surgery conditions was similar.

Figure 2 shows the postural parameters (surface and variance of speed of the $\mathrm{CoP}$ ) measured during the four experimental conditions: before surgery (pre), with prisms (prism), 1 month (post 1) and 3 months (post 2) after surgery, for the two distances (near and far).

Concerning the surface of the CoP (Fig. 2A), the ANOVA showed a significant effect of condition $\left(F_{(3,24)}=\right.$ $4.38, p<.04)$. The surface of the CoP increased in the prism condition compared to the condition without prisms; after the surgery (post 1 and post 2), the surface of the CoP decreased. The least significant difference post hoc test showed a significant difference between the pre and prism conditions and between the pre and post 1 and post 2 conditions. There was no significant distance effect.

Figure 2B shows data concerning the variance of speed of the CoP. There was no significant effect of condition or

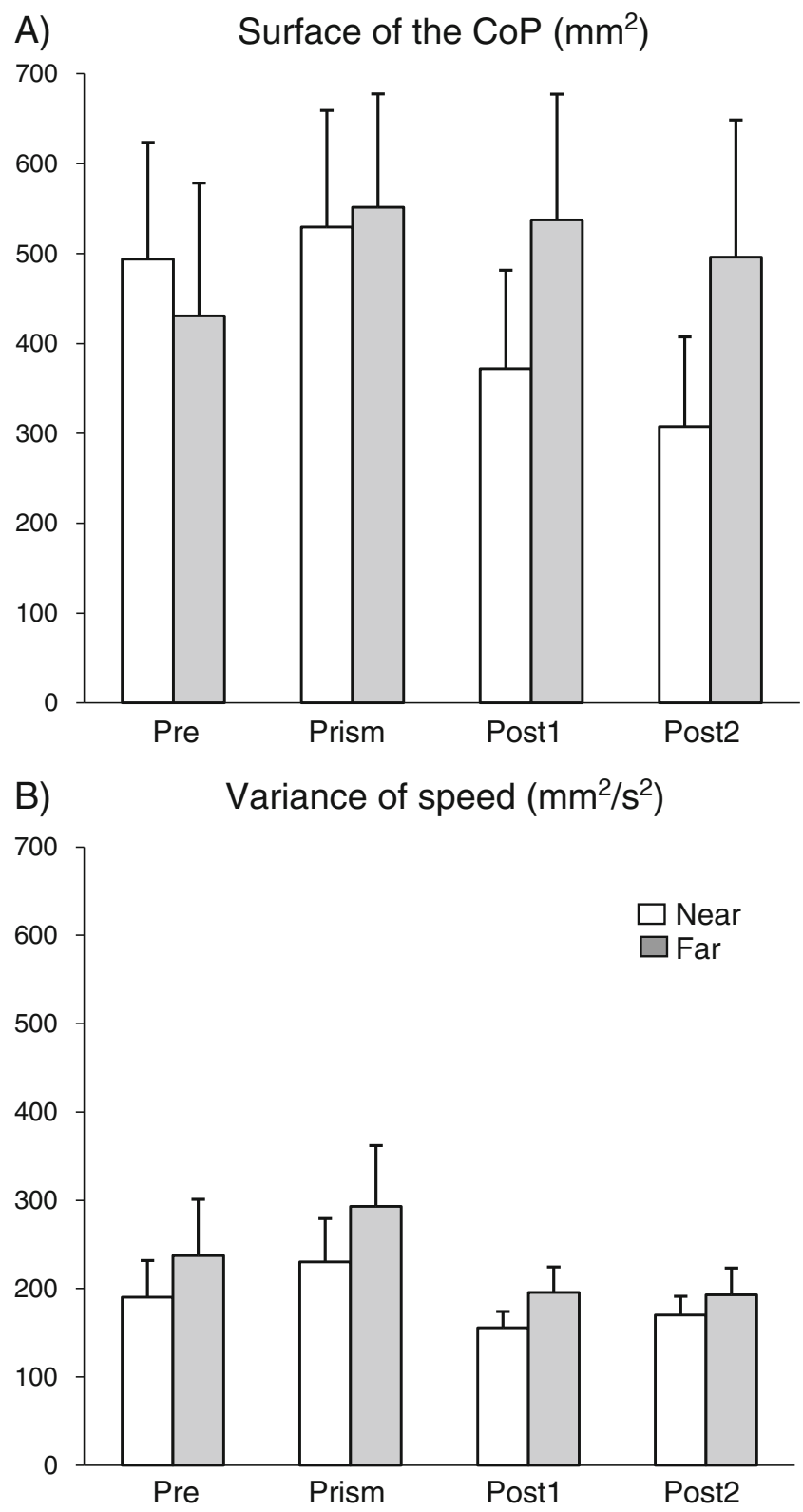

Fig. 2 Means and standard deviations of surface (A) and variance of speed (B) of CoP at different fixation distances (near at $40 \mathrm{~cm}$, far at $200 \mathrm{~cm}$ ) during the different conditions: before surgery without prism, before surgery after prism adaptation, and after eye surgery (post 1 and post 2)

of distance. However, the variance of speed tended to increase in the prism condition and to decrease in the two after-surgery conditions (post 1 and post 2). This was rather similar to what was observed concerning the surface of CoP.

Finally, we should like to point out that our group of children was rather small and we are aware that further postural examinations will need to be performed in the future on more subjects with different types of strabismus and different binocular visual capabilities. 


\section{Discussion}

A prism adaptation test has been used to correct horizontal or vertical deviation in subjects with strabismus, particularly subjects with an acquired deviation [17-19]. For a long time, this test has been used to determine the surgical amount of the recession/resection of the extra-ocular muscle and predict the subject's binocular status after the surgical correction of deviation; [17, 20, 21] however, only the recent study by Matsuo et al. [12] examined the effect of prism adaptation on postural control.

The present study confirms and expands the study by Matsuo et al. [12] showing that adult subjects with strabismus experience poor postural stability while wearing prisms to reduce and/or eliminate eye deviation. Indeed, the data obtained here from strabismic children showed that eye alignment by wearing prisms is not sufficient to improve postural stability. One hour after putting prisms on, body sway is significantly larger than in the condition without prisms. In other words, it is not sufficient to realign the eyes with prisms to induce better postural control; this is corroborated by the fact that the deviation measured after prism wearing was similar to those assessed after surgery. Most likely, other mechanisms are needed to ensure good postural stability. Such mechanisms can be activated via eye alignment only after eye surgery. Indeed, as already shown in our previous study [9] and confirmed here, eye surgery improves postural stability at least a few weeks after eye surgery; proprioceptive inputs associated with extra-ocular muscles are also influenced by surgery. Indeed, it is well known that eye surgery alters the proprioceptive information of the derived eye [22]. According to our previous report, [9] proprioceptive mechanisms modified by eye surgery could improve visual and motor perception, allowing for better control of postural capabilities. Finally, one should also recall that other inputs, such as vestibular and cerebellar capabilities, can be used by these children to improve their postural abilities.

Near distance does not improve postural stability in strabismic children

Unlike normal children and children with vergence abnormalities [2], children with strabismus do not show significantly improved postural stability when focusing at a near distance. This finding is new. Indeed, Brandt's group [23-26] reported that postural stability was better at a near than a far distance because of the increase in visual motion signals. For example, for geometric reasons, the angular size of retinal slip is higher at near than at far distances; consequently, detection of slip and body sway compensations are greater at near distance. As well, motion parallax (relative motion of far versus near targets) is an important visual stimulus for stabilization [27]. All of these authors also suggested that oculomotor convergence inputs, together with proprioceptive information related to the convergence of the eyes, could improve postural control at near distance.

It is well known that vergence eye movements are poor in strabismic children in terms of speed and accuracy, but as Bucci et al. [11] showed, their performance improves after eye surgery. These authors suggested that poor vergence before surgery could be attributed more to the weakness of the sensory input for vergence (e.g., disparity processing) than to a deficit in the vergence control system itself. In contrast, after surgery, binocular processing disparity improves, leading to a switch to a binocular-driven slow vergence mechanism. In the present study, we showed that this binocular vergence system, particularly convergence inputs, even after eye surgery, are not good enough to lead to better postural control at near distance, as is observed in normal children. For strabismic subjects, even after eye surgery, fixating a target at near distance (needing convergence of the eyes) is a difficult task and the efferent and afferent oculomotor signals related to convergence angle are still deficient. On the other hand, one could also hypothesize that visual motion signals are not correctly used by strabismic children, most likely because of their depth perception problem, as has been suggested by Thompson and Nawrot [28] in motion parallax tests.

\section{Conclusions}

In conclusion, this report shows that the re-alignment of the eyes with prisms temporarily affected postural stability: body sway increase. In contrast, the re-alignment of eyes by strabismus surgery improved strabismic children's postural stability. This improvement was probably due to the longer period after eye surgery. We suggest that both the prismatic adaptation test and eye surgery affect the motor and sensory inputs controlling the equilibrium of children with strabismus that they have already developed. The absence of improvement at near distance in children with strabismus was probably due to their vergence deficiency.

Acknowledgements The authors thank the children who participated in the study, Florence Groffal for managing the children's appointments, and Zofia Laubitz for correcting our English.

\section{References}

1. Brandt T (2003) Vertigo. Its Multisensory Syndromes, 2nd edn. Springer, London

2. Bucci MP, Le TT, Wiener-Vacher S, Bremond-Gignac D, Bouet A, Kapoula Z (2009) Poor postural stability in children with 
vertigo and vergence abnormalities. Invest Ophthalmol Vis Sci 50:4678-84

3. Friedrich M, Grein HJ, Wicher C, Schuetze J, Mueller A, Lauenroth A, Hottenrott K, Schwesig R (2008) Influence of pathologic and simulated visual dysfunctions on the postural system. Exp Brain Res 186:305-14

4. Peterka RJ (2002) Sensorimotor integration in human postural control. J Neurophysiol 88:1097-118

5. Ravaioli E, Oie SK, Kiemel T, Chiari L, Jeka J (2005) Nonlinear postural control in response to visual translation. Exp Brain Res 160:450-9

6. Von Noorden GK, Campos EC (2006) Binocular Vision and Ocular Motility. Theory and Management of Strabismus, 6th edn. Mosby, St. Louis, MO

7. Odenrick P, Sandstedt P, Lennerstrand G (1984) Postural sway and gait of children with convergent strabismus. Dev Med Child Neurol 26:495-9

8. Matsuo T, Narita A, Senda M, Hasebe S, Ohtsuki H (2006) Body sway increases immediately after strabismus surgery. Acta Med Okayama 60:13-24

9. Legrand A, Bui-Quoc E, Wiener-Vacher S, Ribot J, Lebas N, Milleret C, Bucci MP (2011) Postural control in children with strabismus before and after surgery. Neurosciences Letters 501 (2):96-101

10. Bucci MP, Kapoula Z, Eggert T, Garraud L (1997) Deficiency of adaptative control of binocular coordination of saccades in strabismus. Vis Res 37:2767-77

11. Bucci MP, Kapoula Z, Yang Q, Roussat B, Bremond-Gignac D (2002) Binocular coordination of saccades in strabismic children before and after surgery. Invest Ophthalmol Vis Sci 43:1040-7

12. Matsuo T, Yabuki A, Hasebe K, Shira YH, Imai S, Ohtsuki H (2010) Postural stability changes during the prism adaptation test in patients with intermittent and constant exotropia. Invest Ophthalmol Vis Sci 51:6341-7

13. Howard IP, Rogers BI (2002) Seeing in Depth. I. Porteous, Toronto, ON

14. Moutakis K, Stigmar G, Hall-Lindberg J (2004) Using the KM visual acuity chart for more reliable evaluation of amblyopia compared to the HVOT method. Acta Ophthalmol Scand 82:547-51

15. Vuillerme N, Chenu O, Pinsault N, Fleury A, Demongeot J, Payan Y (2008) Can a plantar pressure-based tongue-placed electrotactile biofeedback improve postural control under altered vestibular and neck proprioceptive conditions? Neuroscience 155:291-6
16. Geurts AC, Nienhuis B, Mulder TW (1993) Intrasubject variability of selected force-platform parameters in the quantification of postural control. Arch Phys Med Rehabil 74:1144-50

17. Kutschke PJ, Scott WE (2004) Prism adaptation in visually mature patients with esotropia of childhood onset. Ophthalmol 111:177-9

18. Ela-Dalman N, Velez G, Thacker N, Britt MT, Velez FG (2006) Maximum motor fusion combined with one-hour preoperative prism adaptation test in patients with acquired esotropia. J AAPOS 10:561-4

19. Kassem RR (2008) A pilot study of the value of prism adaptation in planning strabismus reoperations. J Pediatr Ophthalmol Strabismus 45:98-103

20. Repka MX, Connett JE, Scott WE, the Prism Adaptation Study Research Group (1996) The one-year surgical outcome after prism adaptation for the management of acquired esotropia. Ophthalmology 103:922-928

21. Ohtsuki H, Hasebe S, Kono R, Shiraga F (1999) Prognostic factors for successful surgical outcome with preoperative prism adaptation test in patients with superior oblique palsy. Acta Ophthalmol Scand 77:536-540

22. Steinbach MJ, Smith DR (1981) Spatial localization after strabismus surgery: evidence for inflow. Science 18; 213 (4514):1407-1409

23. Brandt T, Paulus W, Straube A (1986) Vision and posture. In: Bles $\mathrm{W}$, Brandt $\mathrm{T}$ (eds) Disorders of Posture. Elsevier Science Publishers, Amsterdam

24. Bles W, Kapteyn TS, Brandt T, Arnold F (1980) The mechanism of physiological height vertigo. II. Posturography. Acta Otolaryngol 89:534-540

25. Paulus W, Straube A, Krafczyk S, Brandt T (1989) Differential effects of retinal target displacement, changing size and changing disparity in the control of anterior/posterior and lateral body sway. Exp Brain Res 78:243-252

26. Paulus WM, Straube A, Brandt T (1984) Visual stabilization of posture. Physiological stimulus characteristics and clinical aspects. Brain 107:1143-1163

27. Guerraz M, Sakellari V, Burchill P, Bronstein AM (2000) Influence of motion parallax in the control of spontaneous body sway. Experimental Brain Research 131:244-252

28. Thompson AM, Nawrot M (1999) Abnormal depth perception from motion parallax in amblyopic observers. Vis Res 39:14071413 